International Journal of Management and Sustainability

2021 Vol. 10, No. 4, pp. 104-113.

$\operatorname{ISSN}(e):$ 2306-0662

$\operatorname{ISSN}(p): 2306-9856$

DOI: 10.18488/journal.11.2021.104.104.113

(C) 2021 Conscientia Beam. All Rights Reserved.

check for
updates

\title{
THE EFFECTS OF MARKET AND MACROECONOMIC UNCERTAINTIES ON CORPORATE INVESTMENT DECISIONS IN NIGERIA
}

\section{Jonathan Oniovosa OSOSUAKPOR}

\author{
PhD, AMJU Unique Microfinance Bank Limited, Effurun-Warri, Delta \\ State, Nigeria. \\ Email:ososuakpor@yahoo.com
}

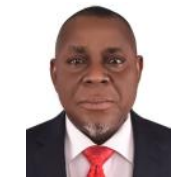

ABSTRACT

\section{Article History}

Received: 10 August 2021 Revised: 30 September 2021 Accepted: 3 November 2021 Published: 6 December 2021

\section{Keywords}

Market uncertainty

Macroeconomic uncertainty

Corporate investments

Economic growth

Real option theory

JEL Classification E22; B22; G111.
In this paper, the effect of market and macroeconomic uncertainties on corporate investment decisions was examined using the real option investment theory. Two types of uncertainties were investigated: macroeconomic uncertainties (exchange, interest and inflation rates) and market uncertainty (stock market volatility) while corporate investments were measured as the sum of the changes in capital stock and depreciation. Data were obtained for the period 2005-2019 and the Generalized Autoregressive Conditional Heteroskedasticity $(\mathrm{GARCH})$ estimation technique was employed. The results showed a significant difference between the effects of macroeconomic and market uncertainties on corporate investment decisions. We found that macroeconomic uncertainty of inflation rate has positive relationship with corporate investments, with a coefficient of 0.35071 , and interest rate uncertainty (0.15567) and exchange rate uncertainty (-0.07852) were also statistically significant, whereas the linear market uncertainty has a negative value of -0.00173 and the quadratic market uncertainty (0.00520) was statistically insignificant. Therefore, interest rate volatility and inflation expectations are not factors constraining investment growth; however, exchange rate uncertainty exerts a substantial negative influence on corporate investment in Nigeria. Given the findings, the study recommends, among others, an appropriate and stable exchange rate policy that makes for easy business planning and forecasting by rational investors. To achieve a stable exchange rate that would bring about increased investment, the government should implement efficient macroeconomic policies, such as those that minimize the structural rigidities in the economy.

Contribution/Originality: This study contributes to the existing literature on the effects of market and macroeconomic uncertainties on corporate investment decisions using a Generalized Autoregressive Conditional Heteroskedasticity model. The study establishes that while macroeconomic inflation rate uncertainty positively affects corporate investments, linear and quadratic market uncertainty negatively affect corporate investments.

\section{INTRODUCTION}

The effect of market and macroeconomic uncertainties on corporate investment outlays is a top priority and has been extensively debated in the economic literature. The previous literature has upheld uncertainty as a significant factor affecting investment, although its effect on investment can be either positive or negative (Abel \& Eberly, 1994; Bekoe \& Adom, 2013; Belke \& Kronen, 2017; Bonga, 2019; Dixit \& Pindyck, 1994; Menzie \& Laurent, 2017; Panagiotidis \& Panagiotidis, 2019). The connection between uncertainty and investment has been strongly established in the literature, particularly in developed countries, where most of the empirical research has taken place. 
Tito and Filho (2007); Belke and Kronen (2017) and Panagiotidis and Panagiotidis (2019) opined that market and macroeconomic uncertainties decrease economic growth, and should therefore be avoided whenever possible. Because uncertainty can result in instability in economic variables, it may adversely affect economic growth via the channel of investments, production and consumption.

Over the years, Nigeria's aggregate investment profile has been unimpressive; for instance, the reported share of investment has experienced a downward trend, particularly during the period 2001-2012, reaching a low of 5.5\% in 2005. Additionally, the average investment growth rate shows a fall from a peak of 50.8\% in 2006 to a low of 25\% in 2012, largely reflecting a decline in investment. According to the views of Soleymani and Akbari (2011); Donwa and Agbontaen (2010), the decline in Nigeria's investment profile may be linked to market and macroeconomic shocks or instability.

Using the real option theory of investments, Bekoe and Adom (2013); Menzie and Laurent (2017) and Panagiotidis and Panagiotidis (2019) established that market and macroeconomic fundamentals do not promote corporate investment but that, nonetheless, most of the market and macroeconomic fundamentals have strong effects on corporate investment and may perhaps be the reason for the level of instability of corporate investment both in the short and long run in most developed and developing nations of the world.

Again, however, empirical studies based on the real options theory of investment are lacking in Nigeria and the available literature has not adequately addressed the vital role of market and macroeconomic uncertainties in corporate investment. Studies that have used the real option theory to examine the effects of market and macroeconomic uncertainties on corporate investment have mainly focused on developed countries; therefore, this study fills the gap in the literature relating to the effects of macroeconomic and market uncertainties on corporate investment decisions in Nigeria. The remainder of this paper is organized as follows: a review of related literature, followed by the methodology, results, discussion, conclusion and recommendations.

\section{REVIEW OF RELATED LITERATURE}

\subsection{Theoretical Framework}

This paper is rooted in the 'real option theory of uncertainty-investment nexus' proposed by Dixit and Pindyck (1994). Real option theory is a systematic and integrated solution that combines economic and financial theories, management science, statistics and econometric modeling to value investment opportunities and capital expenditure projects. Real option is defined as the possibility, but not the necessity, to take certain business decisions, typically the option of making capital investment in the future.

Indeed, real option theory takes into account the value of managerial flexibility in adapting to unexpected market and macroeconomic developments (Belke \& Kronen, 2017; Leduc \& Liu, 2016). If future events remove, or otherwise reduce to some satisfactory level, the key sources of uncertainty based on the available information, firms may exercise their option and proceed to undertake full-blown investment projects. If, however, uncertainty continues or is not adequately resolved, the period of expiration may be extended or the option allowed to lapse, thus limiting any potential adverse exposure to future losses.

In the presence of uncertainty, investors make a choice of which option methodology to employ among an the array of available options, such as the option to wait, alter the scale of operation (i.e., to expand or to contract), abandon an investment, switch input/output, among others (Bekoe \& Adom, 2013; Belke \& Kronen, 2017; Dixit \& Pindyck, 1994). The most likely outcome is that firms will opt to wait, thus keeping the investment option alive so long as they remain uncertain about the outcomes of macroeconomic and market developments.

Likewise, the higher the level of uncertainty, the higher the value of firms' option to wait. According to McDonald and Siegel (1986), the positive relationship that exists between periods of high uncertainty and the value of the option to wait can be explained by the lack of market information that could assist investors in making an informed investment decision. From this asymmetry follows the fact that under conditions of higher uncertainty, it 
is possible that the underlying market and macroeconomic variables rise to high levels, so that the net return from exercising the option of waiting becomes larger. If the underlying variables fall, the firm may lose funds; however, that will be limited to what has been paid for the option.

Uncertainty, particularly that relating to market and macroeconomic fundamentals, could have a detrimental impact on corporate investments when firms exercise their option to wait. However, the negative effect imposed by the option to wait may change if the firm makes the choice to abandon. More so, the option to abandon will come with extra advantages to investors and firms, since it allows firms to abandon or reverse an investment to reduce the adverse effects that market and macroeconomic downturns may have on the investment project.

Consequently, this option encourages current investments, although this option's effect on investment depends to a large extent on the degree to which investment capital expenditure can be reversed under conditions of uncertainty. From the preceding discourse, it can be deduced that the net effect of the collection of real options on firms' investments may be ambiguous and support various theoretical models, which provides a good background for our empirical study.

\subsection{Uncertainty - Corporate Investments Relationship}

Uncertainty may be defined as the investor's perception of what will happen to their investment in the future if they invest their funds in an economic project now. In other words, investors try to predict the performance of their investment, and such analysis may be impeded by the fact that necessary information may currently be lacking that would inform the investors' decision, or the economic environment may be such that both market and macroeconomic indicators are unpredictable, giving rise to uncertainty about the outcome in the investment arena (Bekoe \& Adom, 2013; Belke \& Kronen, 2017; Dixit \& Pindyck, 1994).

Uncertainty is perceived as a cause of anxiety or decrease in well-being; hence, most investors see uncertainty as detrimental and something to be avoided (Tito \& Filho, 2007). Its effects are transmitted to the economy via investment decisions (Panagiotidis \& Panagiotidis, 2019). Kalckreuth (2000), defined uncertainty as a quality of the investor's mental representation of the world, which cannot be qualified with the same precision as price or output.

Tito and Filho (2007) were of the view that firms usually face uncertainty due to various market and macroeconomic dimensions; for instance, investors face uncertainty about firms' outputs, prices, demands, costs, wages, interest rate and exchange rate, among others. Uncertainty is a significant factor in firms' investment decisions; hence this study has reviewed the theoretical basis for the investment-uncertainty relationship. Various economic theories have identified that the relationship between market and macroeconomic uncertainties and investment passes through several channels, including irreversibility, financing constraints and investors' risk aversion behavior.

Kim and Jung (2011) investigated the relationship between uncertainty and corporate investment behaviour. They relied on the use of specific assets to represent the period of uncertainty in the economy by constructing measures of assets that were specifically based on the stability of these assets across various industries, using exogenous increases in aggregate uncertainty brought about by changes in major economic events prevalent in the economy. They concluded that when there is an increase in uncertainty levels, firms that use more specific assets experienced a more significant decrease in investment than those firms which used fewer specific assets.

\subsection{Market and Macroeconomic Uncertainties}

Nigerian firms are subject to various forms of uncertainty, ranging from market to macroeconomic uncertainties. Market uncertainty arises from the volatility of stock prices which predict the performance of the economic conditions, so that stock market volatility is reflective of the uncertainty that is generally prevalent in the market (Belke \& Kronen, 2017; Leahy \& Whited, 1996; Menzie \& Laurent, 2017; Panagiotidis \& Panagiotidis, 2019). 
According to Ngugi, Murinde, and Green (2002), stock prices and yields provide a benchmark against which the cost of capital used for investment and the return on investment can be judged, even if such capital expenditures are not financed directly through the stock market. Given that investors are assumed to be rational, stock prices provide a unique record of the shifts in investors opinions on firms' prospects. It therefore follows that market uncertainty influences corporate firms' investment decisions via the route of stock price volatility. On the other hand, macroeconomic uncertainty, including uncertainties surrounding interest, foreign exchange, and inflationary rates, is a peculiar feature of the Nigerian economy. These macroeconomic uncertainties, if not properly identified and compensated for, could be detrimental to corporate investments.

Similarly, Bialowolski and Weziak-Bialowolski (2013) examined the external factors that influence corporate investments in Poland. Using variables including the company's receivables, firm size and survey data obtained from individual firms, with a root mean-square error of measurement estimation technique, the study found that payment delay is a vital factor affecting corporate investments. However, the result was overturned when macroeconomic and market variables were introduced, in which case these were found to be the most significant factors influencing Polish companies' corporate investments. Consequently, this study investigates the extent to which market and macroeconomic uncertainties affect corporate investments in Nigeria.

\subsection{Extant Studies}

Previous studies on the effects of macroeconomic and market uncertainties on corporate investment decisions in Nigeria are lacking, as most studies in this area have been conducted in developed countries. Given the dearth of empirical studies in the Nigerian context, a review was conducted of studies in developed countries, alongside the few studies in Nigeria, to compensate for the dearth of empirical evidence in Nigeria. Specifically, the reviewed previous studies span the years 2010-2019. Panagiotidis and Panagiotidis (2019) evaluated the uncertainty and investment relationship in Greece, using 25,000 firms' financial position statements spanning 14 years and 14 sectors. The dynamic factor model and GMM regression estimates of the uncertainty-investment relationship revealed a high degree of heterogeneity among the 14 sectors in Greece. Overall, the study found that uncertainty negatively affects investment performance, and this effect significantly increases during periods of crisis.

In France, Menzie and Laurent (2017) assessed the effects of macroeconomic uncertainty on investment. The macroeconomic uncertainty dimensions they studied included exchange rates, interest rates and capital flows. The capital asset pricing model was used, and their findings indicated that the studied macroeconomic uncertainty dimensions negatively affected investment. Moreover, the negative effect of volatility in capital flows is greater at low levels of financial development and with lengthier time-to-build lags in industries. Using the Structural Vector Autoregressive model, Belke and Kronen (2017) examined the impact of uncertainty on the macroeconomic variables of production, consumption and investment. Their findings revealed that market uncertainty has a fairly steadily negative impact on the real economy in Europe. Their results implied that market uncertainty decreases general investment, production and consumption. Farla, De Crombrugghe, and Verspagen (2016) examined the macro and micro determinants of firms' investment patterns, using data from 101 emerging and developing economies and adopting multi-levelled probit model. The variables used for macro data included real GDP in constant prices, growth measured in logarithm and change in GDP in respect to the previous year and the degree of financial openness, percentage of interest rate, and countries' institutional development using two proxies property rights protection and indices of corruption and political stability. The variables used for the micro level included total annual expenditure on purchases of equipment and machinery, investment to sales ratio, and capital as a ratio of labor. The study found that both micro and macro determinants contributed to explain investment behavior, and that firms' investment behavior is heterogeneous in nature and has little dependency on a country's macroeconomic settings. In Ghana, Bekoe and Adom (2013) explored the effects of macroeconomic uncertainty on private investment from 1975-2008, using Philip-Hansen co-integration and regression analyses. The 
macroeconomic uncertainty variables studied included exchange rate, capital inflow, inflation rate and interest rate, among others. The results of the Phillip-Hansen co-integration tests confirmed the presence of a long-run equilibrium link between macroeconomic uncertainty and private investments. Moreover, the regression result showed that macroeconomic uncertainty negatively affects private investments, with the exception of real exchange rate volatility. Kim and Jung (2011) evaluated the connection between macroeconomic uncertainty and investment behavior in China. Their study relied on the use of specific assets to address the period of uncertainty in the economy by constructing measures of these assets, specifically based on the stability of assets across various industries, using exogenous increases in aggregate uncertainty brought about by major macroeconomic events. The study found that when there is an increase in the level of macroeconomic uncertainty, firms using more specific assets suffer a larger decrease in investment than those firms which used fewer specific assets. Similarly, Soleymani and Akbari (2011) investigated the relationship between macroeconomic uncertainty (exchange rate uncertainty) and domestic investment in Nigeria, using a dataset covering 1975-2006. The study adopted fixed and random effects over panel data modelling techniques and found a non-linear relationship between macroeconomic uncertainty of exchange rate and domestic investments. Donwa and Agbontaen (2010) studied the trends and dynamics of investment in Nigeria, using a dataset spanning the years 1970-2008. The study adopted a cointegration econometric method to estimate the dynamics of variables such as real and lag values of investments, exchange rates, capital performance and real values of market size, macroeconomic and political stability. Their findings indicated that inertia is responsible for variations in the domestic investment in Nigeria. Also, they were convinced that market fundamentals do not encourage domestic investment and that present values of exchange rates have stronger effects on domestic investment. Furthermore, the macroeconomic condition revealed reasonable levels of instability that reduced the level of domestic investment both in the short and the long run. In view of this review of the previous literature, we therefore hypothesize that:

Hypothesis: There is no significant difference between the effects of macroeconomic and market uncertainties on corporate investment decisions in Nigeria.

\section{METHODOLOGY}

\subsection{Design, Population and Sample}

This paper employed an ex-post facto design, which, according to Kerlinger and Lee (1986), is adequate because it is a substitute for true experimental research and justifiable for use since the data obtained in this study are from secondary sources. The population of study comprised of one hundred and sixty-one (161) firms publicly quoted on the floor of the Nigerian Stock Exchange as of December 31 $1^{\text {st }}$, 2019. Notably, financial institutions were excluded from the study sample, thus retaining only firms in the real sector; the rationale for the exclusion of financial institutions is because firms in the real sector engage in real investment instead of portfolio investment. Hence, a final sample of seventy-three (73) firms was obtained, and the market and macroeconomic uncertaintyinvestment relationships were based on real option theory of investment.

\subsection{Variables Description and Model Specification}

Data were obtained for market and macroeconomic uncertainties as well as corporate investment fundamentals. Dataset for the models spanned from 2005-2019 and obtained from the Nigerian Stock Exchange, National Bureau of Statistics and the Central Bank of Nigeria (CBN) statistical bulletin. First, some macroeconomic uncertainty variables that could influence corporate investment decision were employed to include exchange, interest and inflation rates; second, market uncertainties was measured via stock price volatility, which predicts the performance of economic conditions; and third, corporate investment is the sum of the changes in capital stock and depreciation.

To test for the effects of market and macroeconomic uncertainties and corporate investment nexus following (Sarkar, 2000) on real option model, the following models were specified: 


$$
\begin{aligned}
\mathrm{I} / \mathrm{K} & =\alpha_{o^{+}} \alpha_{\imath}(\mathrm{c} / \mathrm{f}) / \mathrm{K}+\alpha_{2} \mathrm{UmL}+\alpha_{s u} m H+\varepsilon \\
\mathrm{I} / \mathrm{K} & =\alpha_{o+} \alpha_{l}(\mathrm{c} / \mathrm{f}) / \mathrm{K}+\alpha_{2} \mathrm{UmL}+\alpha_{s u} m H+\alpha_{t}(I / K)_{t-1}+\psi V \varepsilon
\end{aligned}
$$

Where: $I=$ Corporate investment; $K=$ Capital stock; $C / f=$ Cash flow to capital stock; $U m L=$ Proxy for linear uncertainty measure - low measure of uncertainty; $U m H=$ Proxy higher uncertainty measure - high measure of uncertainty; and $(I / K)_{t-1}=$ lagged investment to capital ratio; $\alpha=$ Beta; $\varepsilon=$ Error term.

The variables in the model described in Equation 2, scaled by the firm's capital stock, were used to account for differences in firm sizes, which, according to Bialowolski and Weziak-Bialowolski (2013), influence corporate investments. Uncertainty constitutes the variable of interest, and the inclusion of market and macroeconomic uncertainties in the model is driven by the theoretical and empirical background, indicating that they affect corporate investment decisions. Given that corporate investment decisions are influenced by various uncertainties, and we do not know which of the uncertainties has the most significant impact on corporate investment decisions, another model of corporate investment decisions, which integrates diverse proxies of market and macroeconomic uncertainties, was estimated as Equation 3:

$$
\mathrm{I} / \mathrm{K}=\alpha_{\mathrm{o}}+\alpha_{1}(\mathrm{cf}) / \mathrm{K}+\alpha_{2} \mathrm{u}_{\mathrm{mL}}+\alpha_{3} \mathrm{U}_{\mathrm{mH}}^{2}+\alpha_{4}(1 / \mathrm{k}) \mathrm{t}_{-1}+\beta_{1} \text { Ureer }+\beta_{2} \text { Urint }+\beta_{3} \mathrm{Uinf}+\varepsilon
$$

Where: Ureer $=$ Volatility of exchange rate; Urint $=$ Volatility of interest rate; and Uinf $=$ inflation rate volatility. All other variables specified in Equation 3 are as previously defined.

The prediction equation was estimated using fixed effect and Generalised Least Squares (GLS). The fixed effect model takes into consideration the potential presence of heteroskedasticity and was adopted to account for individual specific effects. Thus each individual firm has its own intercept, showing individual heterogeneity. The choice of fixed effect was driven by the fact that members of the pool (individual firms) were selected at random rather than based on data considerations, which is the case in most panel studies where the individuals are firms or countries; thus, it is suitable to adopt fixed effect model. More importantly, the volatility of variables was measured using standard deviation and, where applicable, Generalized Autoregressive Conditional Heteroskedasticity (GARCH) models. For market uncertainty, a panel data estimation technique was used, while for uncertainty proxies GARCH $(1,1)$ was used for data with high volatility, and standard deviation from a geometric Brownian process for data with low volatility (Bollerslev, 1986). Specifically, the study used the GARCH model of volatility which assumes that variance of error terms is non- constant over time, which is often the case with stock market data.

\section{RESULTS AND DISCUSSION}

Table-1. Descriptive statistics of market and macroeconomic uncertainties of corporate investment determinants model.

\begin{tabular}{c|c|c|c|c|c}
\hline Period & Mean IK & Mean CFK & Mean UEXR & Mean UINF & Mean UINTR \\
\hline 2005 & 5.259251 & 1.538100 & 14.26394 & 6.346684 & 3.228244 \\
\hline 2006 & 3.028980 & 1.688613 & 13.11140 & 6.391287 & 3.382123 \\
\hline 2007 & 4.220916 & 1.576339 & 13.33914 & 6.736821 & 2.057320 \\
\hline 2008 & 4.400878 & 1.939006 & 14.14027 & 7.130080 & 2.070211 \\
\hline 2009 & 3.314066 & 2.253554 & 14.94773 & 7.561522 & 2.213149 \\
\hline 2010 & 3.151125 & 1.190631 & 15.52917 & 7.793462 & 2.318519 \\
\hline 2011 & 3.575278 & 1.529356 & 15.69795 & 8.386910 & 2.280553 \\
\hline 2012 & 3.070425 & 1.550357 & 10.23508 & 8.685141 & 1.930976 \\
\hline 2013 & 2.965579 & 1.845651 & 4.718494 & 9.965353 & 0.641898 \\
\hline 2014 & 2.058642 & 1.847432 & 4.691218 & 4.233454 & 0.766312 \\
\hline 2015 & 1.951293 & 1.927500 & 0.551543 & 1.979899 & 0.968736 \\
\hline 2016 & 1.831411 & 2.013477 & 0.983586 & 1.449569 & 4.999245 \\
\hline 2017 & 1.711529 & 2.099454 & 1.415629 & 0.919239 & 2.029754 \\
\hline 2018 & 1.591647 & 2.185431 & 1.847672 & 0.388909 & 3.060260 \\
\hline 2019 & 1.471765 & 2.271408 & 2.279715 & -0.141421 & 4.090770 \\
\hline
\end{tabular}


Table 1 presents the descriptive statistics of the market and macroeconomic uncertainties that may influence corporate investment decisions in Nigeria. The table shows that the rising inflation expectation is detrimental to investment, as reflected in standard deviation of the inflation variable over the period. The same can be said of exchange rate volatility, which is inversely related to the all-time low investment profile in Nigeria.

Again, the interest rate risk underwent a gradual decline over the 15-year period to 2019. Yet, this considerable improvement in the interest rate does not appear to have positively influenced investment behavior in Nigeria, as indicated by the annual averages of investment. It can generally be deduced that firms' investments appear to have fallen in tandem with the volatility of the stock market variable (i.e., cash flow). Also, the country's significant exchange rate depreciation and rising inflation expectation influenced firms' investment decisions, as reflected in Table 1.

Table-2. Effect of market and macroeconomic uncertainties on corporate investment.

\begin{tabular}{|c|c|c|c|c|}
\hline \multicolumn{5}{|c|}{ Dependent Variable: LNIK? } \\
\hline \multicolumn{5}{|c|}{ Linear estimation after one-step weighting matrix } \\
\hline Variable & Coefficient & Std. Error & t-Statistic & Prob. \\
\hline $\mathrm{C}$ & -0.16362 & 0.32422 & -0.52449 & 0.63803 \\
\hline LNCFK & 0.03577 & 0.01294 & 2.87380 & $0.00603 * * *$ \\
\hline LNUM & -0.00173 & 0.03549 & -0.05080 & 0.99877 \\
\hline LNUM2 & 0.00520 & 0.01749 & 0.30874 & 0.79662 \\
\hline LNUEXR & -0.07852 & 0.02409 & -3.38815 & $0.00125 * * *$ \\
\hline LNUINF & 0.35071 & 0.04409 & 8.26742 & $0.0000^{* * * *}$ \\
\hline LNUINTR & 0.15567 & 0.02428 & 6.66253 & $0.0000^{*} * *$ \\
\hline R-squared & 0.80856 & \multicolumn{2}{|c|}{ Mean dependent var } & 1.29305 \\
\hline Adjusted R-squared & 0.78502 & \multicolumn{2}{|c|}{ S.D. dependent var } & 1.09328 \\
\hline S.E. of regression & 0.48912 & \multicolumn{2}{|c|}{ Sum squared resid } & 182.770 \\
\hline F-statistic & 35.69912 & \multicolumn{2}{|c|}{ Durbin-Watson stat } & 1.80587 \\
\hline
\end{tabular}

Note: The standard errors are heteroskedasticity consistent. One (*), two (**) and (***) stars denote statistical significance at the 10,5 and 1 percent level, respectively. All the variables are expressed in natural logarithm; LNUEXR: Volatility of Exchange Rate; LNUINF: Inflation Expectation; LNUINTR: Interest Rate Variability; all other variables are as previously defined.

Table 2 reports the fixed effect estimates of both the market and macroeconomic variables that are perceived to be relevant in the determination of corporate investment in Nigeria. In addition to the standard investment variables linked to the macroeconomic and market variables of interest, inflation and exchange rates were incorporated into the model. The outcome of our regression indicates that the inflation expectation coefficient has a positively effect that is statistically significant at one percent, suggesting that inflation uncertainty is not a deterrent to firms' investment decisions in Nigeria.

Inflation is taken as a summary measure of the overall macroeconomic condition, and the volatility of its unpredictable component can therefore be considered an indicator of overall macroeconomic uncertainty. By extension, inflation uncertainty does not encourage the exercise of real options to slow down investment in Nigeria. Interest rate variability exhibited characteristics similar to the inflation variable.

The coefficient of determination of the interest rate on corporate investment is positive over the study period and is statistically significant at one per cent. The interest rate is closely linked to the cost of capital; hence, high interest rate volatility can be considered a good indicator of the uncertainty of aggregate investment cost. As expected, the high volatility of this variable makes price signals less informative about the relative profitability of investment across sectors, which could negatively affect investment decisions.

The results show that interest rate volatility is not detrimental to an increase in firm-level investment in Nigeria. Regarding the relationship between exchange rate volatility and corporate investment in Nigeria, the result indicates a negative relationship with a coefficient value of -0.07852, which is statistically significant at one percent, suggesting that firms' investment decisions are highly sensitive to exchange rate fluctuations. Exchange 
rate is related to the relative profitability of investment in diverse economic sectors. This result implies that exchange rate volatility is an important determinant of investment in Nigeria.

The coefficient of cash flow in the model is still very well determined and is statistically significant in its current form. Cash flow has again been revealed as positively related to corporate investment in Nigeria. In contrast, the linear market uncertainty indicator has a negatively signed coefficient, though its value is not significantly different from zero. Overall, the model indicates that greater importance should be attached to the macroeconomic variable of exchange rate volatility as the key deterrent of corporate investment in Nigeria.

In general, since the study makes use of annual information, inertia needs to be taken into account. Thus, the study included the lagged dependent variable among the investment determinants. The results are presented in Table 3.

Table-3. Effect of Inertia on Corporate Investment (IK (-1)).

\begin{tabular}{|c|c|c|c|c|}
\hline \multicolumn{5}{|c|}{ Dependent Variable: LNIK } \\
\hline \multicolumn{5}{|c|}{ Linear estimation after one-step weighting matrix } \\
\hline Variable & Coefficient & Std. Error & t-Statistic & Prob. \\
\hline $\mathrm{C}$ & -0.62071 & 0.35307 & -1.82713 & 0.08231 \\
\hline LNCFK & 0.04043 & 0.01415 & 2.96968 & $0.00457 * * *$ \\
\hline LNUM & 0.00116 & 0.03432 & 0.03517 & 1.01124 \\
\hline LNUM2 & 0.00375 & 0.01692 & 0.23029 & 0.85711 \\
\hline LNUEXR & -0.07736 & 0.02376 & -3.38330 & $0.00125 * * *$ \\
\hline LNUINF & 0.33364 & 0.04338 & 7.99394 & $0.0000^{* * *}$ \\
\hline LNUINTR & 0.15734 & 0.02408 & 6.79204 & $0.0000^{* * * *}$ \\
\hline $\operatorname{IK}(-1)$ & 0.01504 & 0.00604 & 2.58829 & $0.01351 * * *$ \\
\hline R-squared & 0.85438 & \multicolumn{2}{|c|}{ Mean dependent var } & 1.29207 \\
\hline Adjusted R-squared & 0.83332 & \multicolumn{2}{|c|}{ S.D. dependent var } & 1.15053 \\
\hline S.E. of regression & 0.49001 & \multicolumn{2}{|c|}{ Sum squared resid } & 166.344 \\
\hline F-statistic & 42.16311 & \multicolumn{2}{|c|}{ Durbin-Watson stat } & 1.93513 \\
\hline
\end{tabular}

Note: Standard errors are heteroskedasticity consistent. One $(*)$, two $(* *)$ and $(* * *)$ stars denote statistical significance at 10,5 and 1 percent level, respectively; $\operatorname{IK}(-1)=$ lagged dependent variable scaled by capital Stock. All variables in this model are as previously defined.

Table 3 examines the effect of inertia on corporate investment weighted by capital stock. Specifically, the study considers the lagged dependent variable to allow for a possible dynamic structure among the variables. The result of the regression shows that the coefficient of the lagged dependent variable is relatively low, but positive and statistically significant, suggesting that inertia is relevant to any explanation of the variations in corporate investment decisions in Nigeria.

In the model, all the other variables used as argument are positive and statistically significant, except the linear and quadratic market uncertainties which display very slightly positive coefficients which are statistically insignificant. Overall, the study has found that macroeconomic uncertainties have a more significant effect on firms' corporate investment decisions than market uncertainty in Nigeria; this has led to the rejection of the formulated hypothesis that macroeconomic uncertainties have the same impact on corporate investment decisions.

The foremost implication from this study stems from the striking finding that exchange rate uncertainty sends negative signals to rational investors in Nigeria, suggesting the sensitivity of investors to policies on the external sector. It follows that to achieve the desired results, a sound exchange rate should be combined with the appropriate monetary and fiscal policies; this stance will compensate for the volatility of exchange rate. According to Servén (2003), a weak financial system is associated with a significant link between a negative exchange rate and corporate investment uncertainty.

Another major finding of the study concerns the issue of firms' cash flow. According to Vermeulen and Mizen (2004), the financial system is the key determinant of firms' cash flow sensitivity. Firms with unsound financial health are more sensitive to cash flow issues. A high degree of sensitivity of investment to cash flow implies that 
investors have financial constraints. In all the models, cash flow showed how important financing is to corporate investment decisions.

The results of our study corroborate the prior results of Panagiotidis and Panagiotidis (2019); Menzie and Laurent (2017); Bekoe and Adom (2013); Soleymani and Akbari (2011) that macroeconomic uncertainty measures, particularly exchange rate, have a significantly negatively effect on corporate investments. However, given the gap in the literature on market and macroeconomic uncertainties and corporate investment decisions in Nigeria, this study is one of the first to establish the fact that macroeconomic uncertainties do not have the same impact as market uncertainty on corporate investment decisions in Nigeria.

\section{CONCLUSION AND RECOMMENDATIONS}

This paper investigated the effect of market and macroeconomic uncertainties on the level of corporate investment decisions based on the real option investment theory. Two types of uncertainties were assessed for their ability to influence corporate investment decisions - macroeconomic and market uncertainties. Market uncertainty was proxied by stock market volatility, while macroeconomic uncertainties were captured in the exchange, interest and inflation rates; corporate investments were measured as the sum of the changes in capital stock and depreciation.

Interestingly, the GARCH results showed significant differences between the effects of macroeconomic and market uncertainties on corporate investment decisions. Specifically, macroeconomic uncertainties (exchange, interest and inflation rates) jointly exert greater significant effects on corporate investment decisions in Nigeria than market uncertainty (stock market volatility). Nevertheless, we found that interest rate volatility and anticipated inflation are not factors constraining the growth of investment in Nigeria; exchange rate uncertainty, however, exerts a substantial negative influence on corporate investment. More importantly, when it comes to investment decisions, macroeconomic uncertainties are a greater deterrent for firms.

Given the findings of the study, we recommend an appropriate and stable exchange rate policy that makes for easy business planning and forecasting by rational investors. To achieve a stable exchange rate that would bring about increased investment, the government should implement efficient macroeconomic policies, such as those that minimize the structural rigidities in the economy. Moreover, priority should be given to the productive sector when allocating foreign exchange, to limit the uncertainty of the foreign exchange rate. Additionally, monetary and fiscal discipline is advocated to limit the uncertainty of the exchange rate, which, by extension, would promote development in the country through an increase in investment.

Regarding our findings on interest rate volatility and inflation uncertainty, the study presumes that stability of the macroeconomic environment and interest rate policy will spur investment. To achieve a sustainable macroeconomic stability, there should be proper coordination and harmonization of monetary and fiscal policies. This would engender confidence in economic agents and assure investors that the government's policies are credible and predictable. In line with the effect of cash flow sensitivity on investment decisions, we recommend the prompt development of non-depository financial institutions that can act as financial intermediaries and work in competition with the depository banks to instill the much-desired market discipline. By extension, this would check the behavior of the banks - which could make the market more efficient.

This study contributes to the existing literature on the effects of market and macroeconomic uncertainties on corporate investment decisions using a Generalized Autoregressive Conditional Heteroskedasticity model. The study establishes that while macroeconomic inflation rate uncertainty positively affects corporate investments, linear and quadratic market uncertainty negatively affect corporate investments.

Funding: This study received no specific financial support.

Competing Interests: The author declares that there are no conflicts of interests regarding the publication of this paper. 


\section{REFERENCES}

Abel, A. B., \& Eberly, J. C. (1994). American economic association. The American Economic Revierw, 84(5), 1369-1384.

Bekoe, W., \& Adom, P. K. (2013). Macroeconomic uncertainty and private investment in Ghana: An empirical investigation. International Journal of Economics and Financial Issues, 3(2), 276-293.

Belke, A., \& Kronen, D. (2017). The impact of uncertainty on macro variables: An SVAR-based empirical analysis for EU countries. Ruhr Economic Papers, No. 699.

Bialowolski, P., \& Weziak-Bialowolski. (2013). External factors affecting investment decisions of companies. Economics Discussion Paper No. 2013-44.

Bollerslev, T. (1986). Generalized autoregressive conditional heteroskedasticity. Journal of Econometrics, 31(3), 307-327. Available at: https://doi.org/10.1016/0304-4076(86)90063-1.

Bonga, W. G. (2019). Measuring macroeconomic uncertainty in Zimbabwe. Munich Personal RePEc Archive, No. 94759.

Dixit, A. K., \& Pindyck, R. S. (1994). Investment under uncertainty. New Jersey: Princeton University Press.

Donwa, P., \& Agbontaen, O. O. (2010). The trend and dynamics of determinants of investment in Nigeria. International Review of Business Research Paper 6(6), 153-163.

Farla, K., De Crombrugghe, D., \& Verspagen, B. (2016). Institutions, foreign direct investment, and domestic investment: Crowding out or crowding in? World Development, 88, 1-9. Available at: https://doi.org/10.1016/j.worlddev.2016.08.001.

Kalckreuth, V. U. (2000). Exploring the role of uncertainty for corporate investment decisions in Germany. Deutsche Bundesbank, Economic Research Centre, Discussion Paper No. 5/00.

Kerlinger, F. N., \& Lee, H. B. (1986). Foundations of behavioral research. Texas, USA: Fort Worth Publisher.

Kim, B., \& Jung, K. (2011). Corporate cash holdings and tax- induced debt financing. Asia Pacific Journal of Financing Studies, $37(2), 983-1023$.

Leahy, J. V., \& Whited, T. M. (1996). The effect of uncertainty on investment. The European Journal of Finance, 1(1), 1-11.

Leduc, S., \& Liu, Z. (2016). Uncertainty shocks are aggregate demand shocks. Journal of Monetary Economics, 82, 20-35. Available at: https://doi.org/10.1016/j.jmoneco.2016.07.002.

McDonald, R., \& Siegel, D. (1986). The value of waiting to invest. The Quarterly Journal of Economics, 101(4), 707-727. Available at: https://doi.org/10.2307/1884175.

Menzie, D. C., \& Laurent, F. (2017). Impact of uncertainty shocks on the global economy. Journal of International Money and Finance, $30(1), 1-4$.

Ngugi, R. W., Murinde, V., \& Green, C. J. (2002). Does the revitalisation process really enhance stock market microstructure? Evidence from the Nairobi stock exchange. African Finance Journal, 4(1), 32-61.

Panagiotidis, T., \& Panagiotidis, P. (2019). What is the investment loss due to uncertainty? GreeSE Papers, Paper No. 138.

Sarkar, S. (2000). On the investment-uncertainty relationship in a real options model. Journal of Economic Dynamics and Control, 24(2), 219-225. Available at: https://doi.org/10.1016/s0165-1889(99)00005-6.

Servén, L. (2003). Real-exchange-rate uncertainty and private investment in LDCs. Review of Economics and Statistics, 85(1), $212-$ 218. Available at: https://doi.org/10.1162/rest.2003.85.1.212

Soleymani, M., \& Akbari, A. (2011). The relationship between exchange rate uncertainty and investment in some of Sub-Saharan African Countries. International Journal of Business and Public Management, 1(1), 51-57.

Tito, N. T., \& Filho, S. (2007). Is the investment- uncertainty link really elusive? The harmful effects of inflation uncertainty in Brazil. Working Paper Series No. 157.

Vermeulen, P., \& Mizen, P. (2004). Corporate investment and financial constraints: What drives the relationship? European Central Bank. Working Paper Series No. 485.

Views and opinions expressed in this article are the views and opinions of the author(s), International Journal of Management and Sustainability shall not be responsible or answerable for any loss, damage or liability, etc. caused in relation to/arising out of the use of the content. 